\title{
Carta do Dr. Paul Pittaluga
}

Dear Friends,

It is again a great honor and a true pleasure to be invited to the Simposio Internacional de Flebologia in Belo Horizonte in March 2013. I have kept a wonderful reminder of my previous participation two years ago, with an outstanding welcome and with very nice and thoughtful scientific and human exchanges with all of the collegues.

The organizing committee with Dr Reis-Bastos as its spokesman gives me once again the oportunity to share with you our experience in the field of phlebology where everything is moving very quickly these last years.

There is new approaches for the treatment as well as for the comprehension of the chronic venous insufficiency that have turned upside down the way in which we handle the treatment of varicose veins since 10 years.

This invitation will give to me the opportunity to present the updates about the topics on which we have done new studies or set new pratices with the team of the Riviera Veine Institut:

- preservation of the saphenous Vein for the Surgery of Varices in Nullipara patients;

- update on Varicose Vein Recurrence and its management;

- value of Postoperative Compression after Surgical Treatment: Prospective Study;

- influence on chronic venous insufficiency of primary absence of the great saphenous vein in the saphenous compartment at the thigh.

I look forward to seeing you at Belo Horizonte and participating at this meeting.

With my warm regards.

\section{Dr. Paul PITTALUGA, MD}

Riviera Veine Institut - Nice (France), Monte Carlo (Monaco).

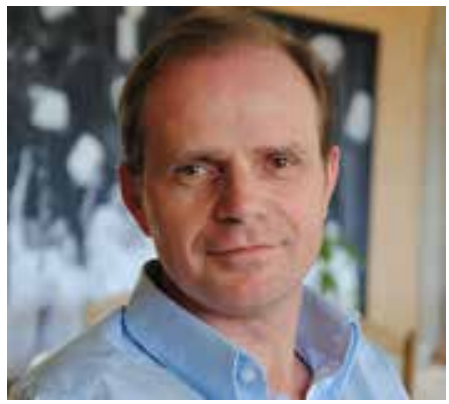

